\title{
Health related quality of life in diabetics during pregnancy - A cross sectional study
}

\author{
CM Pannilaa, RMCJ Rathnayake ${ }^{b}$
}

\begin{abstract}
Objective: To study the health related quality of life of pregnant women with gestational diabetes mellitus and diabetes mellitus during pregnancy.

Method: A cross sectional study done using the SF-36 questionnaire on pregnant women with gestational diabetes mellitus and diabetes mellitus during pregnancy $(n=294)$ and compared with a control group $(n=306)$ of pregnant women.

Results: A total of 600 participated with 294 patients with diabetes and gestational diabetes and 306 controls. The physical component score was lower in the GDM/DM group $(t=1.969)$ showed a significant difference $(\mathrm{P}=0.049, \mathrm{Cl}=0.003-2.87)$ compared to the controls. The mental health score $(t=0.041)$ did not show any significant difference $(\mathrm{P}=0.968, \mathrm{Cl}=-1.45-1.52)$ between the two groups. Sub group analysis of the $8 \mathrm{com}$ ponents showed a significant difference in the physical function component $(P=0.032)$ and the bodily pain component $(P=0.041)$ where the group with gestational diabetes/diabetes group showed a worse health related quality of life. There was no significant difference between physical role $(P=0.125)$ and general health $(P=0.212)$ the other 2 physical health components. All 4 mental health components of the two groups, Vitality $(P=0.744)$, social function $(P=0.235)$, emotional role $(P=0.856)$ and mental health $(P=0.464)$ did not show any significant difference.
\end{abstract}

Conclusion: The physical health of gestational diabetes mellitus/diabetes mellitus pregnant women was lower than that of healthy pregnant women while there is no difference in the mental health between them.

Key words: health related quality of life, pregnancy, gestational diabetes mellitus, diabetes mellitus

Sri Lanka Journal of Obstetrics and Gynaecology 2018; 40: 39-45

DOI: http://doi.org/10.4038/sljog.v40i2.7845

\section{Introduction}

Since 1948, when the World Health Organization (WHO) defined health as being not only the absence of disease and infirmity but also the presence of physical, mental and social well-being, quality-of-life issues have become steadily more important in health care practice and research ${ }^{1}$. A patient's quality of life total physical, mental, and social well-being has come to be viewed as a critical outcome of disease treatment and control. Studies show relatively low correlations between clinical measures of disease activity (e.g., peak flow rates for asthma and haemoglobin A1c $\left[\mathrm{HbA}_{1 \mathrm{C}}\right]$ results for diabetes) and patients perceptions of health and well-being ${ }^{2}$. The goals of clinical interventions in gestational diabetes are to improve not only medical outcomes but health status and health-related quality of life (HRQOL) as well ${ }^{3,4,5}$. Gestational diabetes

a Acting Consultant Obstetrician and Gynaecologist, Army Hospital Colombo, Sri Lanka.

${ }^{\mathrm{b}}$ Senior Lecturer and Consultant Obstetrician and Gynaecologist, Faculty of Medicine, University of Peradeniya, Sri Lanka.

Correspondence: CMP, e-mail: <malikpannila@yahoo.com>

(iD http://orcid.org/0000-0002-7739-4496

Competing interest: The authors report no conflict of interest 
mellitus (GDM) is defined as glucose intolerance with onset or is first detected during pregnancy ${ }^{6}$. It is a common but usually an asymptomatic condition, which causes excessive foetal growth and can lead to significant perinatal and maternal complications. Treating GDM, even mild cases, significantly reduces the rate of certain adverse perinatal and maternal outcomes ${ }^{7,8}$. Available diabetes prevalence data in Sri Lanka show a definite upward trend. According to the data from recently published studies, Sri Lanka is among the countries with the highest diabetes prevalence rates in the world. According to estimates, there should be 2.8 million adults with diabetes mellitus (DM) in Sri Lanka at present and a significant proportion of this may yet be undiagnosed ${ }^{9,10,11}$. The prevalence of diabetes in Sri Lanka is higher in the urban population compared with rural $16.4 \%$ vs. $8.7 \%$. Overall, $21.8 \%$ (20.5-23.1\%) had some form of dysglycaemia. The projected diabetes prevalence for the year 2030 is $13.9 \%^{12}$.

The National Institute for Health and Clinical Excellence (NICE) guidelines categorize South Asians as a group with independent risk factor for $\mathrm{GDM}^{13}$. These new diagnostic criteria are based primarily on the levels of glucose associated with a 1.75-fold increased risk of giving birth to large-for-gestational age infants (LGA) in the Hyperglycaemia Adverse Pregnancy Outcome (HAPO) study ${ }^{14,15,16}$. As diabetes during pregnancy (gestational diabetes and pre gestational diabetes) is on the rise, pregnant women will have to undergo invasive treatment for a tight blood sugar control. They will be subjected to frequent invasive monitoring and also treatment with insulin. There will be more visits to the pregnancy care provider. All these will reduce the health related quality of life of the pregnant women. The objective of the health care provider should not be only control of blood sugar levels but also help women achieve a good health related quality of life. The assessment of the health related quality of life therefore becomes essential to identify the problems the pregnant women with diabetes will be facing.

The Short Form-36 (SF-36) has been used in a great variety of clinical and research settings and has demonstrated a capacity to effectively discriminate between subjects with different conditions and between subjects with different levels of severity for same disease ${ }^{17}$. The SF-36 has also demonstrated a capacity to detect significant treatment effects in a variety of patient populations. For these reasons, the SF-36 is a useful measure to employ in comparing the current health status of different illness-affected populations as well as their responses to specific treatments. It is recommended for use in health policy evaluations, general population surveys, clinical research, and clinical practice. SF 36 has been validated and used in many countries including Sri Lanka. It has been validated in Sri Lanka by Abeyratne ${ }^{18}$ using the 5 -stage process proposed by Flaherty et al ${ }^{19}$ and used in many studies in Sri Lanka ${ }^{18,20,21,22}$.

The purpose of our study was to assess the health related quality of life of patients with diabetes in pregnancy as diabetes in pregnancy is one of the main medical complication of pregnancy in Sri Lankan women. In addition they will have to undergo invasive blood sugar monitoring, often invasive treatment of their condition with insulin and also will have multiple hospital admissions for optimal blood sugar control.

\section{Methodology}

This was a cross sectional study conducted at Teaching Hospital, Peradeniya, Sri Lanka. This study was conducted from September 2011 to September 2012. All consecutive women who attended the antenatal clinics, admitted to the antenatal ward (Ward 10 , Teaching Hospital Peradeniya) and meeting the criteria for enrolment in the study were invited to participate in the study. Ethical clearance was obtained from the Ethical Review Committee, University of Peradeniya, Sri Lanka. Women with diabetes during pregnancy (gestational diabetes and pre gestational diabetes) were chosen as study subjects and pregnant women with a normal uncomplicated pregnancy were chosen as controls. Pregnant women with other medical or pregnancy related complications and women who did not consent to the study were excluded.

SF-36 measures health-related quality of life along 8 different domains: physical functioning, role limitations due to physical problems, bodily pain, general health perception, vitality, social functioning, role limitations due to emotional problems and mental health. In SF-36 the scores are calculated for 8 sub-scales from 0 to 100 (0: worst; 100: best) $)^{23}$.

The SF-36 generates two types of scores (Figure 1) ${ }^{23}$. To generate scores for the eight SF-36 scales, items are summed without weighting or standardization. To generate scores for the two SF-36 summary measures, scale scores are weighted and combined. Although the eight scales provide a more comprehensive profile of health status, the two summary measures have features that make them more advantageous for clinical trials. These include better measurement precision, smaller confidence intervals, the elimination of floor and ceiling effects, simpler analysis by reducing the number of 


\begin{tabular}{|ll|}
\hline 3a & Limited doing vigorous activities \\
3b & Limited doing moderate activities \\
3c & Limited lifting or carrying groceries \\
3d & Limited climbing several flights of stairs \\
3e & Limited climbing one flight of stairs \\
$3 f$ & Limited bending, kneeling, stooping \\
$3 \mathrm{~g}$ & Limited walking more than a mile \\
$3 \mathrm{~h}$ & Limited walking half a mile \\
$3 \mathrm{i}$ & Limited walking one hundred yards \\
$3 \mathrm{j}$ & Limited bathing or dressing yourself \\
\hline
\end{tabular}

4a Cut down amount of time spent on work 4b Accomplished less than would like

4c Limited in the kind of work

4d Difficulty performing the work

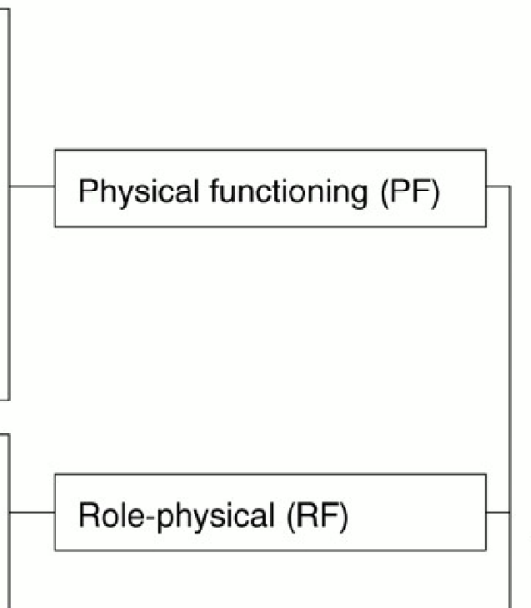

Physical health (PCS)

7 Pain - magnitude

8 Pain - interference with work

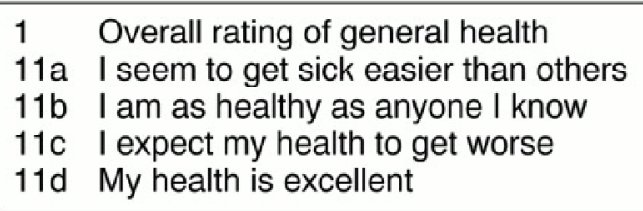

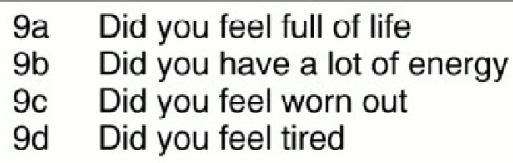

\section{Social activities - extent of limitations} 10 Social activities - time of limitations
Bodily pain (BP)

\section{General health $(\mathrm{GH})$}

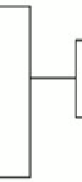

\section{Vitality $(V T)$}

Social functioning (SF)

Role-emotional (RE)

Mental health $(\mathrm{MH})$ 9b Have you been a nervous person

9c Have you felt down in the dumps

9d Have you felt calm and peaceful

9f Have you felt downhearted and low

3h Have you been a happy person

\section{Figure 1.23}

statistical tests required and avoiding the problem of multiple testing, and superior (theoretically) responsiveness. Summary measures are also more easily interpreted as their scores are directly related to scores for the general population, which have been transformed to a mean of 50 and an SD of 10 . The validated short form 36 questionnaire was administered to all who met the inclusion criteria. The measurement model of the SF- $36^{21}$ hypothesizes that 35 of the 36 items are grouped into eight multi-item scales (physical functioning $(\mathrm{PF})$, role limitations physical (RP), bodily pain (BP), general health perceptions (GH), energy/ vitality (VT), social functioning (SF), role limitations emotional (RE), and mental health (MH) that are aggregated into two summary measures (physical component (PCS), mental component (MCS). 
The SF-36 has a single item covering change in health status over the last year and 8 multi-item scales. Two summary scales (Physical and Mental) have also been derived using factor analytic methods. Scales are set up so that a higher score indicates better health. To achieve this, responses on 10 items are recorded before being added to other items on the same scale. Raw scale scores are then transformed to a 0-100 scale. This was done using formulae provided by the developers of SF-36 to analyze the data by standardization of the 8 SF-36 scales, weighting and aggregation of the 8 SF-36 scales and transformation of the aggregate scale score to a T-score.

The $\mathrm{T}$ test was used to analyze the final outcome of PCS and MCS as these have been converted to parametric statistics. The subgroup analysis of the each component was done using Mann-Whitney U test. SPSS version 21 was used as the statistical package to analyze the data. Sample size calculations were done based on previous studies using SF-36. Sample Size ${ }^{24}$ was calculated using the following formula,

$\mathrm{N}=\underline{2\left(\mathrm{Z}_{1-\alpha / 2}\right.}+\underline{\mathrm{Z} 1-\beta)}+\underline{\mathrm{Z}}^{\underline{2}} \underline{1-\alpha / 2}^{2}$ where $\mathrm{d}$ is the standardized difference, defined as $\mathrm{d}=\delta / \sigma$ and $\sigma$ is the population SD of the measurements (21.27) and effect size was assume to be moderate (0.5). It was determined that a sample size of 280 in each arm would be adequate to demonstrate a significant difference between groups (power of 0.80 , $\alpha$ error of 0.05 ).

\section{Results}

600 pregnant women were recruited for the study. The distribution of age of the study population ranged from 18 to 43 years. Of these, the group with GDM/ DM was 294 in number with a mean age of $28.32 \pm$ 5.076 years and the control group was 306 in number with a mean age of $28.15 \pm 5.075$ (Table 1,2).

Comparison of mean age distribution within the two study populations (GDM/DM group vs. control) showed no significant difference $(p=0.417)$. This confirmed that the two study groups showed the same characteristic with regard to age. The body mass index (BMI) of the groups also did not show any significant difference. This indicated that the groups showed similar characteristics with regard to BMI.

Table 1 - Demographic characteristics of study population

\begin{tabular}{|l|l|l|c|}
\hline & $\begin{array}{l}\text { GDM/DM group } \\
(\mathrm{n}=294)\end{array}$ & $\begin{array}{l}\text { Control group } \\
\mathrm{n}=306)\end{array}$ & P value \\
\hline Age (Years) & $28.3(5.07)$ years & $28.2(5.08)$ years & 0.417 \\
$\begin{array}{l}\text { Body mass index } \\
\left(\mathrm{kg} / \mathrm{m}^{2}\right)\end{array}$ & $25.3(4.1) \mathrm{kg} / \mathrm{m}^{2}$ & $24.5(5.3) \mathrm{kg} / \mathrm{m}^{2}$ & 0.152 \\
\hline
\end{tabular}

Distribution of parity in the study groups are displayed below (Table 2). The distribution of parity showed similar distribution with the highest being primipara in both groups accounting for 52.3\% in the GDM/DM group and $53.6 \%$ in the control group.

Table 2 - Parity of patients of the study population

\begin{tabular}{|ccccccc|}
\hline Parity & \multicolumn{2}{c}{ Total } & \multicolumn{2}{c|}{ GDM/DM } & \multicolumn{2}{c|}{ Control } \\
\hline & $\mathrm{N}=600$ & $\%$ & $\mathrm{~N}=294$ & $\%$ & $\mathrm{~N}=306$ & $\%$ \\
\hline 1 & 314 & 52.3 & 150 & 51.0 & 164 & 53.6 \\
2 & 165 & 27.5 & 89 & 30.3 & 76 & 24.8 \\
3 & 5 & 12.5 & 41 & 13.9 & 34 & 11.1 \\
4 & 43 & 7.2 & 12 & 4.1 & 31 & 10.1 \\
5 & 3 & 0.5 & 2 & 0.7 & 1 & 0.3 \\
& 600 & 100 & 294 & 100 & 306 & 100 \\
\hline
\end{tabular}


The HRQOL related to physical component score was lower in the GDM/DM group and showed a significant difference $(\mathrm{P}=0.049)$. The mental health score did not show any significant difference $(\mathrm{P}=0.968)$ between the two groups (Table 3 ).

Table 3 - Analysis of PCS and MCS

\begin{tabular}{|l|l|l|l|}
\hline & \multicolumn{3}{|c|}{ T test } \\
\hline & $\mathrm{t}$ & $\mathrm{p}$ & $95 \%$ confidence interval \\
\hline PCS & 1.969 & 0.049 & $0.003-2.87$ \\
MCS & 0.041 & 0.968 & $-1.45-1.52$ \\
\hline
\end{tabular}

Analysis of components of PCS and MCS shows the following (Table 4).

Table 4 - Sub group analysis of patients with GDM/DM vs. control group

\begin{tabular}{|l|c|c|c|c|}
\hline & $\begin{array}{l}\text { Patients } \\
\text { GDM/DM } \\
(\mathrm{n}=294)\end{array}$ & $\begin{array}{c}\text { Control group } \\
(\mathrm{n}=306)\end{array}$ & Z score & $\begin{array}{l}\text { P value } \\
\text { (Independent } \\
\text { sample Mann - } \\
\text { Whitney U test })\end{array}$ \\
\cline { 2 - 4 } & median & median & 2.145 & 0.032 \\
\cline { 1 - 3 } Physical functioning (PF) & 50 & 60 & 1.532 & 0.125 \\
Role physical (RP) & 40 & 40 & 2.045 & 0.041 \\
Bodily pain (BP) & 70 & 65 & 1.248 & 0.212 \\
General health (GH) & 57 & 60 & 0.327 & 0.744 \\
Vitality (VT) & 60 & 60 & 1.188 & 0.235 \\
Social functioning (SF) & 70 & 70 & 0.182 & 0.856 \\
Role emotional (RE) & 80 & 63 & 0.732 & 0.464 \\
Mental health (MH) & 60 & 75 & \\
\hline
\end{tabular}

Sub group analysis of the 8 components showed a significant difference in the physical function component $(\mathrm{P}=0.032)$ and the bodily pain component $(\mathrm{P}=0.041)$ where the group with $\mathrm{GDM} / \mathrm{DM}$ showed a worse HRQOL. There was no significant difference between physical role $(\mathrm{P}=0.125)$ and general health $(\mathrm{P}=0.212)$ the other 2 physical components. The mental health components of HRQOL between the two groups Vitality $(\mathrm{P}=0.744)$, social function $(\mathrm{P}=0.235)$, emotional role $(\mathrm{P}=0.856)$ and mental health $(\mathrm{P}=0.464)$ did not show any significant difference.

\section{Discussion}

The results shows a slight but significantly worse physical component summary scale (PCS) in the GDM/ DM group compared to controls $(\mathrm{p}=0.032)$. This was due to impairment in physical function and bodily pain score. PF (physical function) measures the daily physical activity of a person. The GDM/DM group could have limited physical function due to risk factors such as being obese and also carrying a larger baby and also development of polyhydramnios due to GDM 
or DM although the BMI at the booking visit were similar in both groups. The significant difference in bodily pain could be due to the fact that the group with GDM/DM would need repeated admissions to the hospital for regular blood sugar monitoring and some times injection of insulin. The other components of the physical component summary scale such as general health and work related activity measured by RF (physical role) did not show any significant difference between the two groups. Multiple significant testing was has been done as per guide on SF 36 analysis.

Raw scale scores are transformed to a 0-100 scale. Because the increment changes due to different componants for each subgroup these data are considered non parametric. But the final results are transformed into parametric data and converted to a T-score.

There have been many studies that have evaluated health related quality of life during pregnancy in healthy women using the SF-36, and in also diabetic individuals. Only a few studies have focused on HRQOL of patients with GDM/DM with regard to pregnancy, all having been during the post partum period with no studies being done to assess the HRQOL of patients with GDM or DM during pregnancy.

Otchet $^{25}$ et al. showed diminished scores along the same SF-36 dimensions including physical functioning, role limitation due to physical health, bodily pain, vitality, and social functioning during pregnancy. But research has not been done on pregnant women with medical or obstetric complications. A control group had to be chosen from the pregnancy population itself to offset the already diminished HRQOL during pregnancy. The standard values given for a normal population was not used as the values would be different in a pregnant population compared to a normal standard population, and the HRQOL was compared to a pregnancy population of similar age gestation as the HRQOL deteriorates with advancing gestation.

By contrast there was no significant difference in the mental health component between the two groups. This could be due to the fact that all these pregnant mothers in their late pregnancy were expecting their babies within a few days and they were looking forward for a joyous event in their life. None of the ism group components of the mental health summary scale showed any significant difference between the 2 groups. These include vitality, their social functioning, emotional role and mental health status.
In conclusion pregnant women with GDM/DM showed a significantly lower HRQOL with regard to physical component summary scale than their health pregnant counterparts. However there was no difference in the Mental Health component between the two groups.?

\section{References}

1. Constitution of the World Health Organization. World Health Organization. Handbook of basic documents. 5th ed. Geneva: Palais des Nations, 1952: 3-20.

2. Stewart AL, Hays RD, Ware JE Jr. The MOS short-form general health survey: reliability and validity in a patient population. Med Care 1988; 26: 724-35.

3. Testa MA, Simonson DC. Assessment of quality of life outcomes. N Engl J Med. 1996; 334(13): 835-40.

4. Guyatt G, Feeny D, Patrick D. Measuring healthrelated quality of life. Ann Intern Med. 1993; 118: 622-9.

5. Mackeigan LD, Pathak DS. Overview of healthrelated quality-of-life measures. American Journal of Hospital Pharm. 1992; 49: 2236-45.

6. American College of Obstetricians and Gynecologists Practice Bulletin. Clinical management guidelines for obstetrician-gynecologists. Number 30, September 2001. Obstetrics and Gynecology 2001; 98: 525-38.

7. Karakash SD, Einstein FH. Diabetes in pregnancy: glyceamia control guidelines and rationale. Current Opinion Endocrinology Diabetes Obestetrics. 2011; 18(2): 99-103.

8. Crowther CA, Hiller JE, Moss JR, McPhee AJ, Jeffries WS, Robinson JS, for the Australian Carbohydrate Intolerance Study in Pregnant Women (ACHOIS) Trial Group. Effect of treatment of gestational diabetes mellitus on pregnancy outcomes. N Engl J Med. 2005; 352(24): 2477-86.

9. Katulanda P, Sheriff MHR, Matthews DR. The diabetes epidemic in Sri Lanka - a growing problem. Ceylon Medical Journal. 2006; 51(1): 26-28.

10. Wijewardena K, Mohideen MR, Mendis S, Fernando DS, Kulathilaka T, et al. Prevalence of hypertension, diabetes and obesity: baseline findings of a population based survey in four 
provinces in Sri Lanka. Ceylon Medical Journal 2005; 50: 62-70.

11. Illangasekera U, Rambodagalla S, Tennakoon S. Temporal trends in the prevalence of diabetes mellitus in a rural community in Sri Lanka. Journal of Royal Society of Health 2004; 124: 92-4.

12. Katulanda P, Constantine GR, Mahesh JG, et al. Prevalence and projections of diabetes and prediabetes in adults in Sri Lanka - Sri Lanka Diabetes, Cardiovascular Study (SLDCS), Diabetic medicine. 2008; 25(9): 1062: 1069.

13. National Institute for Health and Clinical Excellence (NICE) website. www.nice.org.uk/CG062/(28 January 2012)

14. Lawrence JM, Contreras R, Chen W, Sacks DA. Trends in the prevalence of preexisting diabetes and gestational diabetes mellitus among a racially / ethnically diverse population of pregnant women, 1999-2005. Diabetes Care 2008; 31: 899-904.

15. Ryan EA. Diagnosing gestational diabetes. Diabetologia. 2011 March; 54(3): 480-6.

16. Metzger BE, Lowe LP, Dyer AR, Trimble ER, Chaovarindr U, Coustan DR, et al. HAPO Study Cooperative Research Group, Hyperglycemia and adverse pregnancy outcomes. N Engl J Med. 2008; 358: 1991-2002.

17. Dorman P, Slattery J, Farrell B, et al. Qualitative comparison of the reliability of health status assessments with EuroQol and SF-36 questionnaires after stroke. 1998; 29: 63-8.

18. Abeyratne K. Health Related Problems of Returnee Female Middle East Migrants and Need of the
Families Left Behind. Colombo, Sri Lanka: University of Colombo; 2003.

19. Flaherty JA, Gaviria FM, Pathak D, et al. Developing instruments for cross-cultural psychiatric research. J Nerv Ment Dis. 1988; 176: 257-63.

20. Wijesinghe RS, Wickremasinghe AR, Physical, Psychological, and Social Aspects of Quality of Life in Filarial Lymphedema Patients in Colombo, Sri Lanka. Asia Pac J Public Health, 1010539511434140, February 2, 2012.

21. Lansakara N, Wickramasinghe AR, Seneviratne HR. Feeling the Blues of Infertility in a South Asian Context: Psychological Well-Being and Associated Factors Among Sri Lankan Women with Primary Infertility. Women \& Health 2011; 51(4): 383-99.

22. Madarasingha NP, de Silva P, Satgurunathan K Validation study of Sinhala version of the dermatology life quality index (DLQI). Ceylon Medical Journal. 2011; 56: 18-22.

23. Ware JE Jr, Kosinski MA, Keller SD. SF-36 physical and mental health summary scales: a user's manual. Boston, MA: The Health Institute, New England Medical Centre, 1994

24. Julios SA, George S, Campbell MJ. Sample size for studies using the short form 36 (SF-36). Journal of Epidemiology and Community Health 1995; 49: 642-44.

25. Otchet F, Carey S, Adam L. 1999. General health and psychological symptom status in pregnancy and the purperium: what is normal? Obstetrics and Gynecol., 94: 935-41. 